This item was submitted to Loughborough's Research Repository by the author.

Items in Figshare are protected by copyright, with all rights reserved, unless otherwise indicated.

\title{
Elite handcycling: A qualitative analysis of recumbent handbike configuration for optimal sports performance
}

PLEASE CITE THE PUBLISHED VERSION

https://doi.org/10.1080/00140139.2018.1531149

\section{PUBLISHER}

(c) Informa UK Limited, trading as Taylor \& Francis Group

\section{VERSION}

AM (Accepted Manuscript)

\section{PUBLISHER STATEMENT}

This is an Accepted Manuscript of an article published by Taylor \& Francis in Ergonomics on 9 January 2019, available online: http://www.tandfonline.com/10.1080/00140139.2018.1531149.

\section{LICENCE}

CC BY-NC-ND 4.0

\section{REPOSITORY RECORD}

Stone, Benjamin, Barry Mason, Andrea Bundon, and Vicky Goosey-Tolfrey. 2019. "Elite Handcycling: A Qualitative Analysis of Recumbent Handbike Configuration for Optimal Sports Performance". figshare. https://hdl.handle.net/2134/35235. 
Title: Elite Handcycling: A Qualitative Analysis of Recumbent Handbike Configuration for Optimal Sports Performance

Authors: Benjamin Stone ${ }^{1}$, Barry S. Mason ${ }^{1}$, Andrea Bundon ${ }^{2}$, Victoria L. Goosey-Tolfrey ${ }^{1}$ Affiliations:

${ }^{1}$ Peter Harrison Centre of Disability Sport, School of Sport, Exercise and Health Sciences, Loughborough University, Loughborough, United Kingdom.

${ }^{2}$ School of Kinesiology, University of British Columbia, Vancouver, Canada.

Author Contact Details:

Benjamin Stone

Address: NCSEM 1.21, Loughborough University Campus, Loughborough, LE11 3TU

E-mail: B.M.Stone@lboro.ac.ukＴelephone Number: +44 (0)1509226387

Dr. Barry S. Mason

Address: NCSEM 1.21, Loughborough University Campus, Loughborough, LE11 3TU

E-mail: B.Mason@lboro.ac.ukＴelephone Number: +44 (0)1509 226387

Dr. Andrea Bundon

Address: War Memorial Gymnasium, Room 210, 6081 University Boulevard Vancouver, BC V6T 1Z1

E-mail: Andrea.Bundon@ubc.caＴelephone Number: 604-822-9168

Prof. Victoria L. Goosey-Tolfrey

Address: NCSEM 1.26, Loughborough University Campus, Loughborough, LE11 3TU

E-mail: V.L.Tolfey@lboro.ac.uk_Telephone Number: +44 (0)1509226386

Corresponding Author: V. L. Goosey-Tolfrey

Word Count: 4502

Running Head: Handcycling Ergonomics 


\begin{abstract}
:
Our understanding of handbike configuration is limited, yet it can be a key determinant of performance in handcycling. This study explored how fourteen handcycling experts (elite handcyclists, coaches, support staff and manufacturers) perceived aspects of recumbent handbike configuration to impact upon endurance performance via semi-structured interviews. Optimising the handbike for comfort, stability and power production were identified as key themes. Comfort and stability were identified to be the foundations of endurance performance and were primarily influenced by the seat, backrest, headrest and their associated padding. Power production was determined by the relationship between the athletes' shoulder and abdomen and the trajectories of the handgrips, which were determined by the crank axis position, crank arm length and handgrip width. Future studies should focus on quantifying the configuration of recumbent handbikes before determining the effects that crank arm length, handgrip width and crank position have on endurance performance.
\end{abstract}

Keywords: Recumbent Handcycling, Elite Athletes, Qualitative Methods, Disability Ergonomics and Sports Ergonomics

\title{
Practitioner Summary:
}

To gain a greater understanding of the impact of handbike configurations on endurance performance the perceptions of expert handcyclists were explored qualitatively. Optimising the handbike for comfort and stability, primarily via backrest padding, and power production, the position of the shoulders relative to handgrips and crank axis, were critical. 


\section{Introduction}

Handcycling has become a popular recreational and sporting exercise modality for individuals with lower limb impairment (van der Woude et al. 2008). There has been a focus on the handbike as a form of mobility for rehabilitation (Hettinga et al. 2010; Hettinga, Hoogwerf, and van der Woude 2016), for daily ambulation (Arnet, van Drongelen, Veeger, \& van der Woude, 2013) and as a vehicle for recreational (Janssen, Dallmeijer, and van der Woude 2001) and competitive sport (Abel et al. 2006, 2010; Fischer et al. 2014). In a sporting context, handcyclists compete in either arm-powered recumbent handbikes or arm-trunk-powered kneeling handbikes depending on their type and level of impairment (Krämer et al., 2009; Litzenberger et al., 2016). The current study will focus on the recumbent handbike (Figure 1), as four (H1-H4) of the five handcycling classifications (H1-H5) use this style of handbike for racing (UCI 2018).

Since the inception of handcycling at the Paralympic Games in 2004, there have been considerable performance developments in the sport. The physical conditioning, training strategies and preparation of elite handcyclists has improved substantially (Perret 2017). In conjunction with these physiological advancements, the racing handbikes are becoming increasingly lightweight, aerodynamic (Fischer, Figueiredo, and Ardigò 2015) and tailored to meet the specific requirements of each athlete (Litzenberger, Mally, and Sabo 2016). The improvements in the physical conditioning of the athletes and the evolutions in handbike design have contributed to the improved performance levels in handcycling (Perret 2017).

Handcycling performance is dependent upon three factors: the capabilities of the athlete, the design and construction of the equipment (handbike) and the interaction between the athlete and their equipment (Mason, van der Woude, and Goosey-Tolfrey 2013), termed the handbikeuser interface. The physiological capabilities of elite handcyclists and the determinants for success in handcycling have previously been investigated (Abel et al. 2006, 2010; Groen, van 
der Woude, and De Koning 2010; Lovell et al. 2012; Fischer, Figueiredo, and Ardigò 2015). Few studies, however, have investigated the impact of the handbike-user interface or handbike design and construction on endurance performance. Research exploring the impact of the handbike-user interface on performance has focussed on the position and configuration of the cranks in ambulatory (Arnet et al. 2014; Bafghi et al. 2008; Faupin et al. 2006; van der Woude et al. 2008) or recreational handcycling (Abel et al. 2003, 2015; Goosey-Tolfrey, Alfano, and Fowler 2008; Krämer, Hilker, and Böhm 2009; Krämer et al. 2009). Here, the configuration of the handbikes and demands on the participants differ considerably from elite handcycling thus, the influence that specific areas of racing handbike configuration have, on endurance performance, are unknown.
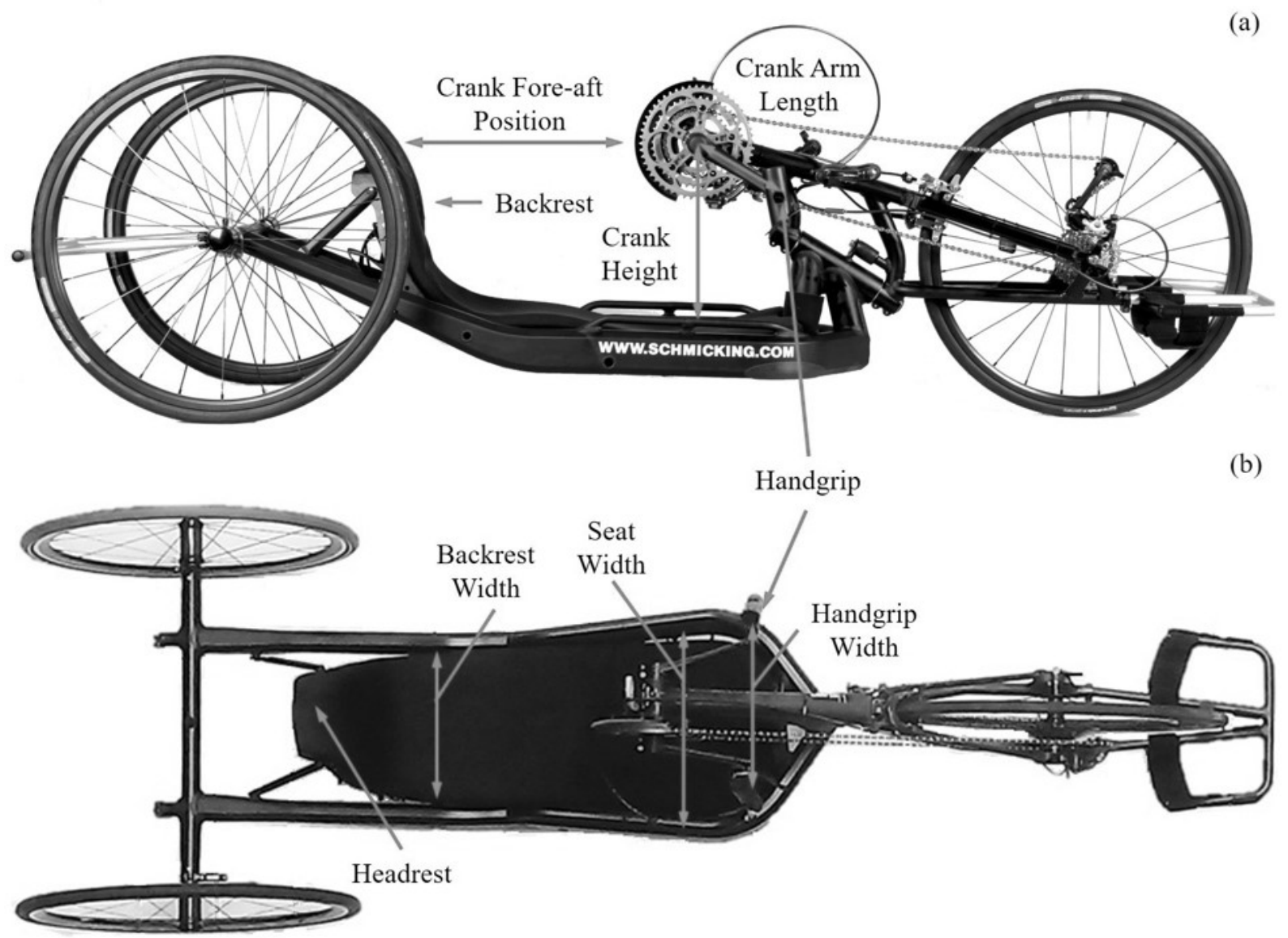

Figure 1: (a) Side-on and (b) overhead view of a recumbent handbike used by elite athletes, illustrating some of the areas of configuration that can be manipulated. 
The configuration of a racing handbike is complex as numerous components can be manipulated under International Cycling Union (UCI) regulations, all of which potentially affect performance. One gap in the literature lies in understanding how handcycling experts (defined as elite handcyclists, their coaches, support staff and handbike manufacturers) would configure a racing handbike to maximise endurance performance. Adopting a qualitative methodology would allow the opinions and experiences of expert handcyclists, who have the experience of configuring numerous racing handbikes, to be considered and understood. Understanding how and why handcycling experts select certain types of equipment and configurations for a racing handbike along with their perceived effects on performance, is a critical step in optimising the performance of a handbike.

The objective of this study was to employ a qualitative methodology to identify the components of handbike configuration and set-up that handcycling experts perceived to have the greatest impact on endurance performance. Similar qualitative approaches have successfully identified priority research areas in power assisted wheelchairs (Giacobbi et al. 2010; Rushton et al. 2017), wheelchair racing (Bundon, Mason, and Goosey-Tolfrey 2017) and wheelchair court sports (Mason et al. 2010; Bundon, Mason, and Goosey-Tolfrey 2017). The findings of this study are intended to inform future research, aiming to optimise recumbent handbike configuration for endurance performance.

\section{Methods}

\section{Participants}

Maximum case sampling was employed to select the handcycling experts to be interviewed in the current study (Sparkes and Smith 2014). As noted by Sparkes and Smith (2014), this sampling method requires the research team to define, before recruitment, dimensions most relevant to the topic under investigation and then systematically recruit 
participants who represent the variants within these dimensions. In this instance, informed by the existing literature and our own experiences of working in disability sport (Bundon, Mason, and Goosey-Tolfrey 2017), the research team focused on the following dimensions: role in sport, time involved in the sport, gender and classification. The final sample included 14 handcycling experts (Table 1).

Table 1: Participant Information

\begin{tabular}{ccc}
\hline Gender & Role in Handcycling & $\begin{array}{c}\text { Handcycling } \\
\text { Experience } \\
\text { (years) }\end{array}$ \\
\hline Male & Athlete - H4 & 6 \\
Female & Athlete - H3 & 3 \\
Male & Athlete - H3 & 8 \\
Female & Athlete - H3 & 21 \\
Male & Athlete - H1 & 11 \\
Male & Manufacturer & 4 \\
Male & Manufacturer & 10 \\
Male & Manufacturer & 16 \\
Male & Coach & 2 \\
Male & Coach & 6 \\
Male & Coach & 15 \\
Male & Support Staff & 3 \\
Female & Support Staff & 9 \\
Male & Support Staff & 17 \\
\hline
\end{tabular}

UCI (2018) classification: H1 Quadriplegia, H3 - H4

paraplegia or severe lower limb impairments

\section{Procedures}

Semi-structured interviews were employed because it allowed the research team to identify specific avenues of inquiry a priori, while still allowing the flexibility for participants to raise new topics and for the researcher to further probe these ideas (Sparkes and Smith 2014). Semi-structured interviews have also proven valuable in that they are first and foremost opportunities for conversations and, as Smith and Sparkes (2016) explain, humans are conversational beings. It is through the social encounter of the conversational interview that we 
get to know each other and gain rich knowledge about the other's world. In this project, we were seeking to better understand not only what 'handcycling experts' knew about the design and construction of handcycles but how they came to know this and the experiences that led them to develop this knowledge. Semi-structured interviews provided the opportunities to explore questions from our prior research and our reading of the academic literature but also allowed the conversation to develop in new and unexpected ways based on what participants shared with us. The interview guide was developed by the research team, two who have extensive knowledge of physiological and biomechanical testing and one with expertise in qualitative methods and methodologies. All team members had considerable prior experience researching and working in disability sport. An experienced handcycling coach reviewed the guide which, following a successful pilot interview, was employed throughout the investigation. The final interview guide covered topics including: performance determinants, the configuration of the handbike-user interface, components of the handbike (Figure 1) and the current process of fitting a recumbent handbike. A conversational interview style was adopted, with participants being encouraged to broadly discuss aspects of racing handbike configuration and design, with the interviewer prompting if a topic identified in the interview guide was not discussed.

All interviews were audio recorded and conducted by the first author under the supervision of an experienced interviewer in person $(n=9)$ or via a Skype video call $(n=5)$. Where possible, participants were asked to bring their recumbent handbike to the meeting as a point of reference. Interviews lasted 83 to 192 minutes giving a total of 1753 minutes of dialogue. Recruitment stopped when the research team started to observe data saturation, the point at which data began to repeat in the interviews and no new trends were emerging (Smith and Sparkes 2016). While we acknowledge that the concept of data saturation is widely debated amongst qualitative sport and exercise researchers (Smith and Sparkes 2016), our decision was 
based largely on agreement amongst the research team that the interviews to date, had resulted in sufficient data to provide new insights into the topic being considered (without suggesting that our work was exhaustive or that speaking with other/more participants would not have provided further insights). Ethical approval for the study was obtained from the university's local ethics committee and all participants provided their written informed consent.

\section{Analysis}

The epistemological framing of the project focused on understanding how recumbent handbike configuration and design impacts performance from the participants' perspective. To achieve this understanding, interviews were transcribed verbatim and a hierarchical content analysis was conducted. Hierarchical content analysis consists of a set of steps designed to assist the researcher(s) in identifying patterns in the data and specifically the interplay between the patterns including any ordering or hierarchy that exists (Sparkes and Smith 2014). This type of analysis allows for a coherent, succinct description of the data and is particularly useful when doing exploratory work (Sparkes and Smith 2014). In this study, the process of analysis included immersion in the data (reading and re-reading of transcripts) while tagging and making note of potential codes. These included deductive codes identified during the project design and inductive codes that arose from field notes taken during the interview process and other codes developed when reading and re-reading the transcripts. In total, 18 codes were identified in the coding process. These codes were placed into clusters and ultimately refined into five distinct, yet interrelated, themes (Table 2). The analysis was performed by the first author and a second member of the research team, experienced in qualitative research, acted as a 'critical reader' throughout the data analyses process to query decisions made and probe for further clarification and refinement of codes. 
Table 2: Description of the identified themes and codes

\begin{tabular}{ccccc}
\hline $\begin{array}{c}\text { Aerodynamics and } \\
\text { Mechanical } \\
\text { Components }\end{array}$ & Comfort & Manoeuvrability & Power Production & Stability \\
\hline Footpods & Fitting & Breaking & Athlete Position & Classification \\
Gearing System & Injury/Pain & Clearance & Crank Axis Position & Strapping \\
Handbike Design & Padding & Handbike & Crank Length & Backrest and \\
Materials & & Dimensions & Handgrip Width & Seat Shape \\
Wheels & & & & \\
\hline
\end{tabular}

\section{Results}

This paper will focus on three of the five superordinate themes; comfort, power production and stability. These groups were selected for more in-depth analysis by the research team as they contained the nodes with the richest data and the most novel insights into how handcycling experts configure a recumbent handbike to optimise endurance performance.

\section{Comfort}

There was a consensus amongst athletes and manufacturers that feeling 'comfortable' in the handbike was critical. Comfort was primarily perceived to be the ability to cycle for long periods, up to 'six-hours' a day, without having to move or re-position to alleviate aches, pains or pressure. A lack of comfort was suggested to have a negative impact on performance:

The comfort of the bike is really important to training. If you are not comfortable on the bike you won't be able to complete the quality of training required to sustain a high level of performance. (Athlete)

Getting them into a seat position where they can sit for a long period of time and not suffer discomfort. If you are not comfortable in a position you will struggle to produce power. (Coach)

In addition to not being able to complete the volume of training required, coaches and support staff associated discomfort with increased injury risk, principally injury to the cervical and thoracic spine and pressure sores. Therefore, discomfort potentially leads to time-off the handbike impacting upon training volume and consequently endurance performance. 
Comfort was frequently discussed in relation to configuring or 'fitting' a recumbent handbike. The primary components of the handbike that contributed to athlete comfort were the backrest, headrest and seat, referred to as the supporting structures. Participants explained that the backrests are manufactured in standard shapes and sizes (e.g. small, medium or large) and commented that the current padding solution was inadequate:

I think there is also scope to do some work on the backrest padding. Currently, it is just a sheet of foam, there is no finesse to it at all. (Athlete)

Creating an optimal set-up for comfort was also thought to be time-consuming and, in some cases, impossible:

Everybody’s backs are shaped differently and with spinal injuries, backs can be fairly strange shapes and unsymmetrical. Additionally, because we do not have sensation it is difficult to know where you need the padding. (Athlete)

I never really found the position that I was comfortable in, I would get backache and I found myself tweaking the backrest for a couple of months after I received it to get into a comfortable position. (Athlete)

Inexperienced athletes, in particular, encountered difficulties altering the shape or size of the backrest or associated padding to maximise comfort. Furthermore, athletes with spinal lesions, causing a lack of sensation, found optimising comfort difficult. These views were reiterated by coaches and support staff who explained the time-consuming trial and error process of adding and removing padding to improve comfort. An individualistic approach appeared essential when optimising the comfort of a handbike.

\section{Stability}

Stability was consistently described as providing the base from which power could be generated. The athletes felt stable in the handbike if their legs, torso and head remained 
'relaxed' or still when they were propelling the handbike. Athletes valued stability, describing it as being ‘attached to’ or 'at one with’ the handbike:

You want to be as compact and as firm in the bike as possible. You don't want any unnecessary movement or sliding up and down on the frame. (Athlete)

A coach identified that stability was one of the main differentiating factors between elite and sub-elite handcyclists:

There will be less body movement, no head wobble, no shoulder movement, the chest will be open, and it will look smooth and glide rather than looking under pressure. There is no loss in efficiency in the delivery of power throughout the whole pedal cycle. (Coach)

There was a consensus amongst participants that while comfort enabled athletes to complete a high training volume, stability in the handbike was the foundation for power generation and ultimately performance.

The principal areas of the handbike that were perceived to impact on stability were the supporting structures and abdominal strapping. To maximise stability participants reported that the backrest and headrest should be positioned and shaped in such a way so that the head and torso were always in 'full contact' with the supporting structures. These supporting structures needed to be rigid as the athletes stated that they would use the backrest and headrest to push off when propelling the handbike. The athletes perceived that the shape and rigidity of the seat, backrest and headrest were critical for stability, facilitating power production.

Participants unanimously stated that an individual's anthropometry and classification also impacted upon the stability of a handcyclist. Athletes with high spinal lesions (H1- H3) are inherently less stable than athletes with lower lesion levels (H4 - H5). To improve stability, H1- H3 athletes used additional abdominal strapping, such as thicker or multiple straps. A 
number of participants proposed the use of bespoke backrests and seats. One participant had a customised seat and backrest:

I can feel benefits from having a little bit more lateral support. Effectively it has given me a bit more core stability which I am lacking because of the lack of available muscle function. (Athlete)

Participants agreed that additional lateral support would be highly beneficial, particularly for the athletes in the H1- H3 classes, and that current solutions are inadequate. However, a number of athletes were concerned about the cost of such bespoke equipment.

\section{Power Production}

The analysis identified four components of the handbike that were unanimously perceived to have a critical effect on power output and efficiency: crank axis position (horizontal and vertical), crank length, handgrip width and the position of the athlete (shoulder and abdomen). These components were thought to determine the propulsion technique of a handcyclist:

It is the relationship between the position of your shoulders, arms and the crank because that is where all the power comes from. If you can get that in exactly the right position so that you can deliver the most power all the way through the crank cycle. That will give you the best performance. (Mechanic)

A clear rationale was presented by participants when discussing the position of the crank axis relative to the shoulders and abdomen. It was stated that the horizontal position of the cranks should result in the elbows being 'slightly bent' when the handgrips are at the furthest point from the shoulders, 'probably $15^{\circ}$ of elbow bend'. If the elbow fully extended or the shoulders protracted it was a sign for coaches and manufacturers that the cranks were too far away from the shoulders. The height of the crank should be as low as possible, ' $12 \mathrm{~mm}$ clearance between the handgrip and my stomach', without having an impact on manoeuvrability. The position of 
the athlete's shoulder, manipulated by the backrest and seat position, should be below the height of the crank axis. This configuration was suggested to be optimal for both reducing air resistance and maximising power output.

The trajectory of the handgrips, primarily influenced by crank arm length and handgrip width, in relation to the shoulders and abdomen, was also crucial. Athletes used crank arms that ranged between $160 \mathrm{~mm}$ and $175 \mathrm{~mm}$ in length because these were the crank lengths provided by the manufacturers. Two athletes had experimented with crank lengths ranging from $160 \mathrm{~mm}$ to $175 \mathrm{~mm}$ and, in agreement with the other participants, felt that changing crank length had a substantial impact on performance. Participants expressed an interest in reducing rather than increasing crank length. All the participants stated that the optimal handgrip width was in line with, or just inside, the line of the shoulders:

Crank width is related to my shoulder width. We decided that as narrow as possible but without getting pressure sores from inside the frame is best. It is aerodynamic and puts you in a biomechanical position that allows you to pedal naturally. (Athlete)

Furthermore, a handgrip width equal to or slightly less than shoulder width was frequently suggested to reduce the incidence of shoulder injury and pain. There was consensus amongst the participants regarding the selection of handgrip width and crank length. However, unlike handgrip width, it was evident that decisions concerning crank length were not based upon a clear logic rationale, such as injury prevention, aerodynamics or maximising power production, but dependent on the crank lengths provided by the manufacturers as they 'work'.

To improve their endurance performance athletes, especially inexperienced ones, frequently changed the configuration of their recumbent handbikes. It was acknowledged that the athletes were involved in a 'trial and error' process based on individual observations, citing 'feel' as a point of reference, or by comparison with other handcyclists. These constant manipulations were seen by coaches, support staff and manufacturers to negatively affect 
performance and potentially cause injury. However, it was accepted that athletes would keep 'fiddling' with their handbike set-up until an optimal set-up was identified objectively, with measures such as cycle kinetics, economy or efficiency being suggested. Additionally, the participants stated that athlete anthropometry, strength, cadence and aerodynamics were also key factors that need to be considered in any future research to ensure that the findings are transferable.

\section{Discussion}

Handcycling experts perceive the configuration of the handbike and handbike-user interface to have a significant impact on endurance performance. The research team identified three themes so that meaningful and novel data could be acquired, these were comfort, stability and power output. It was evident that participants considered the comfort and stability of the structures supporting the torso and head as the foundations for successful performance. Handcycling performance is dependent on maximising power output and efficiency, which was thought to be primarily affected by the position of the athlete about the crank axis and handgrips.

The themes stability and comfort primarily concerned how athletes lie and fit into their recumbent handbikes and were influenced by padding and the supporting structures. The headrest is designed to support the head and cervical spine while the backrest is designed primarily to support the thoracic and lumbar spine. The seat provides support for the pelvis and legs with strapping securing the abdomen. The backrests tend to be manufactured from a single piece of aluminium or carbon fibre, in a small range of sizes, which are then covered with a thin foam cushion, attached by Velcro, providing padding for the athlete. Recumbent handcyclists have a range of disabilities affecting their individual needs for comfort and stability. To improve comfort or stability athletes have to source their own materials, 
considering cost, rigidity, weight and durability, and then design and construct their own unique solution which can be time-consuming and technically challenging. At present the most effective solution is to manufacture a bespoke carbon fibre backrest, moulded to the athletes' torso, however, such components are expensive and will not be available to all competitors. While an athlete may benefit from a bespoke backrest they need to know the type of support they require, a challenge for inexperienced handcyclists, as once built these backrests are not adjustable. Although bespoke solutions are effective the costs are prohibitive, therefore manufacturers need to develop a wider range of sizes and shaped supporting structures and provide more sophisticated customisable padding solutions. This would particularly benefit inexperienced handcyclists who, due to their lack of knowledge, changing fitness levels and potentially changing technique, are potentially more likely to change their handbike set-up more markedly and more frequently than experienced handcyclists.

In the current study, comfort and stability were identified as separate themes. Comfort primarily related to injury reduction while stability facilitated power production. It was apparent that a handcyclist could be comfortable and unstable or vice versa, hence the separation of the themes. A lack of comfort was associated with an increased injury risk, primarily pressure sores or neck injuries, which could affect training and therefore performance. Conversely, a lack of stability, through flexible supporting structures and ineffective lateral support or abdominal strapping, was thought to compromise power production. Optimising comfort was a particular challenge for athletes with spinal lesions, due to their lack of sensation. Similarly, stability was deemed critical for athletes with spinal lesions, especially those with higher lesions (classes H1 - H3), who due to their limited trunk musculature, are less able to stabilise themselves in the handbike. Optimising stability and comfort is an essential and necessary first step in the process of setting up or configuring a handbike. This process was the primary cause of frustration for 
the athletes, especially inexperienced handcyclists, potentially leading to injuries, discomfort and athlete drop-out.

This study provided an initial understanding of the handbike-user interface and its perceived effect on power production. It was revealed that the trajectories of the handgrip, determined by crank axis position, crank length and handgrip width, relative to the athlete's shoulder and abdomen, were identified as the critical components of the handbike-user interface. Positioning and configuring the cranks so that the force-length characteristics and moment arms of the elbow and shoulder are optimal would be logical, as suggested by the coaches and support staff, affirming the suggestion of van Drongelen et al. (2009). Currently, athletes are continually changing and adjusting their handbikes through a subjective 'trial and error' process, with 'feel' consistently being used as an indicator of performance. Consequently, in a population of elite handcyclists, it is likely that there will be a reasonable degree of variation in the position and configuration of the cranks. Thus, quantitative studies need to initially identify the configuration of the handbike-user interface employed by elite recumbent handcyclists.

The position of the athlete's shoulders relative to the crank axis and the handgrip was perceived to determine the technique of a handcyclist. In agreement with participants' responses, the movement of the upper limbs are constrained by the circular path of the handgrips (Gorce and Faupin 2008; Litzenberger Mally, and Sabo 2016). These kinematic investigations have found that the fore-aft position of the crank influences elbow motion, while the height of the crank and the width of the handgrips influence shoulder and wrist kinematics. Crank position also influences upper limb muscle activity (Litzenberger, Mally, and Sabo 2016), but the effects on mechanical efficiency and shoulder load are inconclusive (Arnet et al., 2014; van Drongelen et al. 2009). Quantitative studies manipulating handgrip width have been more conclusive, a handgrip width of $85 \%$ of shoulder width was found to be optimal in a 4-second 
sprint (Krämer, Hilker, and Böhm 2009). Backrest inclination, affecting shoulder height and aerodynamics, has also been investigated by Arnet and her colleagues (2012; 2014). A more reclined position (recumbent position $15^{\circ}$ ) increased shoulder load (Arnet et al. 2014) but reduces air resistance which would lower power output, reducing shoulder load (Arnet et al. 2012), for a given speed on the road. Participants presented a clear, logical and consistent rationale when describing the position of the cranks and width of the handgrips. The cranks should be positioned as low as legally possible, the elbows should be slightly bent when the arms are fully extended and the handgrip widths should be equal to or slightly less than the width of shoulders. Therefore, it is recommended that future studies identify the optimal handgrip width, 'roughly shoulder width', and crank fore-aft position, 'arms slightly bent at full extension', for endurance performance as the current descriptions are vague.

In contrast to crank width and crank axis position, no clear rationale was provided when selecting crank arm length. The crank arm lengths used in handcycling, $160 \mathrm{~mm}$ to $175 \mathrm{~mm}$, are typically the same as those used in leg-powered cycling (Ferrer-Roca et al. 2017). The human arm is approximately 30 \% shorter than the leg (Gordon et al. 1989), yet, the same crank arm lengths are used. Crank arm length determines the length of the handgrip trajectory (de Vey Mestdagh 1998) and, in conjunction with drive wheel diameter and gear ratios, determine the resistance at the handgrip (Martin and Spirduso 2001). Goosey-Tolfrey, Alfano, and Fowler (2008) found that shorter crank arms improve efficiency in handcycling, however, the crank lengths used, $180 \mathrm{~mm}$ to $220 \mathrm{~mm}$, and exercise intensity, $70 \mathrm{~W}$ and $90 \mathrm{~W}$, are not applicable to elite recumbent handcycling. All the participants expressed an interest in shortening crank arm length but, due to cost and difficulties associated with gearing and leverage, it was challenging to manipulate crank arm length in an applied setting. If the crank arm lengths were reduced by $30 \%(5 \mathrm{~cm})$ the crank height and position of the athletes could be lowered potentially improving the aerodynamic situation. 
The findings of the current study can inform the configurations and experimental designs used in future research aiming to optimise the handbike-user interface. Quantitative studies should design methodologies aligning with our handcycling experts' descriptions of handbike configuration. Expert handcyclists unanimously defined handgrip width, crank height and crank fore-aft position relative to shoulder width, shoulder height and elbow angle respectively, considering the participant's anthropometry and position in the handbike. For example, Arnet et al. (2014) manipulated crank height relative to shoulder height while Krämer, Hilker, and Böhm (2009) determined handgrip width relative to shoulder width. Future qualitative studies could also be used to understand what makes an athlete feel comfortable, stable and 'at one’ with their handcycle.

Before manipulating the configuration of the handbike-user interface, studies should focus on gaining an understanding of recumbent handcycling set-up. The research focus can then shift to optimising the handbike-user interface for endurance performance, specific in anthropometry and impairment of the individual. It is imperative that these critical components of the handbike-user interface and other contributing factors, such as aerodynamics, manoeuvrability, cadence and mechanical components are controlled and standardised in future experimental studies. Furthermore, researchers need to be attentive to UCI regulations to ensure that the findings, performance or health-related, can be used to support or challenge these regulations. A great deal of sport-specific research is required, as currently, athletes are making decisions regarding their handbike configuration based on trial and error.

\section{Limitations}

Homogeneity of the sample regarding classification range could be viewed as a limitation (H1, n=1; H3, n=3; H4, n=1) despite the depth of experience. Therefore, an increased number and greater spread of athletes across the classes (H1 and H2) would have been 
advantageous. However, given that this is the first study of its kind to investigate handbike configuration in a sporting context the results should lay the platform for future research to build on.

\section{Conclusions}

It is critical that the configuration of a recumbent handbike facilitates the efficient production of power, from a stable and comfortable position. The study identified comfort and stability as critical considerations for recumbent handcyclists and that the current supporting structures and padding solutions are inadequate and require urgent attention from handbike manufacturers. The research revealed that expert handcyclists unanimously agreed that power output was primarily affected by crank axis position, handgrip width and crank arm length. Currently, athletes' selections, when configuring a recumbent handbike, are based on trial and error potentially limiting performance and increasing injury risk. Therefore, it is essential that further research is undertaken to help handcyclists, particularly inexperienced athletes, optimise their handbike configuration relative to their anthropometry and disability. The current study has identified crank position and crank length as key components worthy of future quantitative investigation.

Acknowledgements: This work was supported by the Engineering and Physical Sciences Research Council under Grant EP/M507489/1 \& supported by the English Institute of Sport. 


\section{References}

Abel, T., S. R. Vega, I. Bleicher, and P. Platen. 2003. "Handbiking: Physiological Responses to Synchronous and Asynchronous Crank Montage.” European Journal of Sport Science 3 (4): 1-9. doi:10.1080/17461390300073401.

Abel, T, B Burkett, S Schneider, R Lindschulten, and H K Strüder. 2010. “The Exercise Profile of an Ultra-Long Handcycling Race: The Styrkeprøven Experience.” Spinal Cord 48 (12): 894-98. doi:10.1038/sc.2010.40.

Abel, T, B Burkett, B Thees, S Schneider, and H K Stueder. 2015. “Effect of Three Different Grip Angles on Physiological Parameters during 2 Laboratory Handcycling Test in AbleBodied Participants.” Frontiers in Physiology 6. doi:10.3389/fphys.2015.00331.

Abel, T, S Schneider, P Platen, and H K Strüder. 2006. "Performance Diagnostics in Handbiking during Competition.” Spinal Cord 44 (4): 211-16. doi:10.1038/sj.sc.3101845.

Arnet, U., S. van Drongelen, M. Schlüssel, V. Lay, L. H. V. van der Woude, and H. E. J. Veeger. 2014. "The Effect of Crank Position and Backrest Inclination on Shoulder Load and Mechanical Efficiency during Handcycling.” Scandinavian Journal of Medicine and Science in Sports 24 (2): 386-94. doi:10.1111/j.1600-0838.2012.01524.x.

Arnet, U., S. van Drongelen, D. H. E. J. Veeger, and L. H. V. van der Woude. 2013. “Force Application during Handcycling and Handrim Wheelchair Propulsion: An Initial Comparison.” Journal of Applied Biomechanics 29 (6): 687-95. doi:10.1123/jab.29.6.687.

Arnet, U, S van Drongelen, L H V van der Woude, and D H E J Veeger. 2012. “Shoulder Load during Handcycling at Different Incline and Speed Conditions.” Clinical Biomechanics (Bristol, Avon) 27 (1). Elsevier Ltd: 1-6. doi:10.1016/j.clinbiomech.2011.07.002. 
Bafghi, H., A. de Haan, A. Horstman, and L. van der Woude. 2008. "Biophysical Aspects of Submaximal Hand Cycling.” International Journal of Sports Medicine 29 (8): 630-38. doi:10.1055/s-2007-989416.

Bundon, A., B. S. Mason, and V. L. Goosey-Tolfrey. 2017. “Expert Users’ Perceptions of Racing Wheelchair Design and Setup: The Knowns, Unknowns, and next Steps.” Adapted Physical Activity Quarterly 34 (2): 141-61. doi:10.1123/apaq.2016-0073.

Drongelen, S. van, J.C. Maas, A. Scheel-Sailer, and L.H.V. Van Der Woude. 2009. “Submaximal Arm Crank Ergometry: Effects of Crank Axis Positioning on Mechanical Efficiency, Physiological Strain and Perceived Discomfort.” Journal of Medical Engineering \& Technology 33 (2): 151-57. doi:10.1080/13561820802565676.

Faupin, A., P. Gorce, P. Campillo, A. Thevenon, and O. Rémy-Néris. 2006. "Kinematic Analysis of Handbike Propulsion in Various Gear Ratios: Implications for Joint Pain.” Clinical Biomechanics 21 (6): 560-66. doi:10.1016/j.clinbiomech.2006.01.001.

Ferrer-Roca, V., V. Rivero-Palomo, A. Ogueta-Alday, J. A. Rodríguez-Marroyo, and J. García-López. 2017. “Acute Effects of Small Changes in Crank Length on Gross Efficiency and Pedalling Technique during Submaximal Cycling.” Journal of Sports Sciences 35 (14). Routledge: 1328-35. doi:10.1080/02640414.2016.1215490.

Fischer, G., P. Figueiredo, and L. P. Ardigò. 2015. "Physiological Performance Determinants of a 22 Km Handbiking Time Trial of a 22-Km Handbiking Time Trial.” International Journal of Physiology and Performance 10 (8): 965-71. doi:10.1123/ijspp.2014-0429.

Fischer, G., C. Tarperi, K. George, and L. P. Ardigò. 2014. “An Exploratory Study of Respiratory Muscle Endurance Training in High Lesion Level Paraplegic Handbike Athletes.” Clinical Journal of Sport Medicine 24 (1): 69-75. doi:10.1097/JSM.0000000000000003.

Giacobbi, P. R., C. E. Levy, F. D. Dietrich, S. H. Winkler, M. D. Tillman, and J. W. Chow. 
2010. "Wheelchair Users' Perceptions of and Experiences with Power Assist Wheels." American Journal of Physical Medicine \& Rehabilitation 89 (3): 225-34. doi:10.1097/PHM.0b013e3181c9d7df.

Goosey-Tolfrey, V. L., H. Alfano, and N. Fowler. 2008. “The Influence of Crank Length and Cadence on Mechanical Efficiency in Hand Cycling.” European Journal of Applied Physiology 102 (2): 189-94. doi:10.1007/s00421-007-0576-7.

Gordon, C. C., T. Churchill, C. E. Clauser, B. Bradtmiller, J. T. McConville, I. Tebbetts, and R. A. Walker. 1989. “1988 Anthropometric Survey of U.S. Army Personnel : Summary Statistics : Interim Report.” Yellow Springs, OH: Natick Labs.

Groen, W. G., L. H. V. van der Woude, and J. J. De Koning. 2010. “A Power Balance Model for Handcycling.” Disability and Rehabilitation 32 (26): 2165-71. doi:10.3109/09638288.2010.505677.

Hettinga, F. J., M. Hoogwerf, and L. H. V. van der Woude. 2016. "Handcycling : Training Effects of a Specific Dose of Upper Body Endurance Training in Females.” European Journal of Applied Physiology 116 (7). Springer Berlin Heidelberg: 1387-94. doi:10.1007/s00421-016-3395-X.

Hettinga, F.J., L. Valent, W. Groen, S. van Drongelen, S. de Groot, and L. H. V. van der Woude. 2010. "Hand-Cycling: An Active Form of Wheeled Mobility, Recreation, and Sports.” Physical Medicine and Rehabilitation Clinics of North America 21 (1): 127-40. doi:10.1016/j.pmr.2009.07.010.

Janssen, T W, a J Dallmeijer, and L H van der Woude. 2001. "Physical Capacity and Race Performance of Handcycle Users.” Journal of Rehabilitation Research and Development 38 (1): 33-40. http://www.ncbi.nlm.nih.gov/pubmed/11322469.

Krämer, C., L. Hilker, and H. Böhm. 2009. “Influence of Crank Length and Crank Width on Maximal Hand Cycling Power and Cadence.” European Journal of Applied Physiology 
106 (5): 749-57. doi:10.1007/s00421-009-1062-1.

Krämer, C., G. Schneider, H. Böhm, I. Klöpfer-Krämer, and V. Senner. 2009. “Effect of Different Handgrip Angles on Work Distribution during Hand Cycling at Submaximal Power Levels.” Ergonomics 52 (10): 1276-86. doi:10.1080/00140130902971916. Litzenberger, S., F. Mally, and A. Sabo. 2016. “Biomechanics of Elite Recumbent Handcycling : A Case Study.” Sports Engineering 19 (3): 1-11. doi:10.1007/s12283016-0206-x.

Lovell, D., D. Shields, B. Beck, R. Cuneo, and C. McLellan. 2012. “The Aerobic Performance of Trained and Untrained Handcyclists with Spinal Cord Injury.” European Journal of Applied Physiology 112 (9): 3431-37. doi:10.1007/s00421-012-2324-x.

Martin, J. C., and W. W. Spirduso. 2001. "Determinants of Maximal Cycling Power: Crank Length, Pedaling Rate and Pedal Speed.” European Journal of Applied Physiology 84 (5): 413-18. doi:10.1007/s004210100400.

Mason, B. S., L. Porcellato, L. H. V. van der Woude, and V. L. Goosey-Tolfrey. 2010. “A Qualitative Examination of Wheelchair Configuration for Optimal Mobility Performance in Wheelchair Sports: A Pilot Study.” Journal of Rehabilitation Medicine 42 (2): 14149. doi:10.2340/16501977-0490.

Mason, B. S., L. H. V. van der Woude, and V. L. Goosey-Tolfrey. 2013. “The Ergonomics of Wheelchair Configuration for Optimal Performance in the Wheelchair Court Sports.” Sports Medicine 43 (1): 23-38. doi:10.1007/s40279-012-0005-x.

Perret, C. 2017. “Elite-Adapted Wheelchair Sports Performance: A Systematic Review.” Disability and Rehabilitation 39 (2): 164-72. doi:10.3109/09638288.2015.1095951. Rushton, P. W., B. W. Mortenson, P. Viswanathan, R. H. Wang, W. C. Miller, L. Hurd Clarke, and CanWheel Research Team. 2017. "Intelligent Power Wheelchair Use in Long-Term Care: Potential Users’ Experiences and Perceptions.” Disability and 
Rehabilitation: Assistive Technology 12 (7): 740-46.

doi:https://doi.org/10.1080/17483107.2016.1260653.

Smith, B., and A.C. Sparkes. 2016. "Interviews: Qualitative Interviewing in the Sport and Exercise Sciences.” In Routledge Handbook of Qualitative Research in Sport and Exercise, edited by B. Smith and C.A. Sparkes. Abingdon, UK: Routledge.

Sparkes, A. C., and B. Smith. 2014. Qualitative Research Methods in Sport, Exercise and Health. Abingdon, UK: Routledge.

UCI. 2018. "UCI Cycling Regulations - Part 16 Para-Cycling.” http://www.uci.ch/mm/Document/News/Rulesandregulation/16/80/73/1-GEN-20160101E_English.pdf.

Vey Mestdagh, K. de. 1998. "Personal Perspective: In Search of an Optimum Cycling Posture.” Applied Ergonomics 29 (5): 325-34. doi:10.1016/S0003-6870(97)00080-X.

Woude, L. H. V. van der, A. Horstman, P. Faas, S. Mechielsen, H. A. Bafghi, and J. J. de Koning. 2008. "Power Output and Metabolic Cost of Synchronous and Asynchronous Submaximal and Peak Level Hand Cycling on a Motor Driven Treadmill in Able-Bodied Male Subjects.” Medical Engineering \& Physics 30 (5): 574-80. doi:10.1016/j.medengphy.2007.06.006. 